\title{
Discussion on the "Double Evaluation" Model of Urban Comprehensive Disaster Prevention Supported by GIS
}

\author{
Xiaozhuo Wang ${ }^{1,2}$, Zhitao Wang ${ }^{1,2}$, Donghui Ma ${ }^{1,2}$, Jingyu $\mathrm{Su}^{1,2}$ \\ 1.College of Architecture and Urban Planning, Beijing University of Technology \\ 2.Institute of Earthquake Resistance and Disaster Reduction, Beijing University of Technology \\ Beijing, China \\ 1021564179@qq.com,wzt@bjut.edu.cn,mdh@bjut.edu.cn,jysu@bjut.edu.cn
}

\begin{abstract}
The evaluation of urban comprehensive disaster prevention is an important part of urban planning work.Starting from the regional disaster system theory,the indicator system was established based on the urban disasterfighting sequence and the type of hazard factor,and the "double evaluation" model of urban comprehensive disaster prevention with equal emphasis on "city disaster assessment capability" and "disaster risk assessment" is constructed.Taking Beijing Changping New City as an example,the GIS platform was used to sort out the disaster prevention resource base map, and the corresponding evaluation indicators were identified and obtained.The model constructed in this paper was used to conduct comprehensive disaster prevention evaluation for the six major districts of Xincheng.According to the evaluation results, the potential disaster risks of the whole city and each district can be reflected.
\end{abstract}

Keywords-Comprehensive disaster prevention; Double evaluation;Evaluation of the ability of cities to withstand disasters; Assessment of disaster risk; GIS ; Changping's new town

\section{INTRODUCTION}

China has entered a new era of socialism with Chinese characteristics. China's urbanization process has also entered the "second half". The development focus has shifted from quantitative improvement to quality improvement and structural optimization. The ability of disaster prevention, mitigation and relief is undoubtedly an important label for the quality of urbanization and also the people. However, the rapid development of the city has made the city's operating system increasingly complex, and the corresponding security risks continue to increase. Through scientific and effective urban comprehensive disaster prevention evaluation, it has found that the shortcomings in urban disaster prevention and mitigation have become an indispensable basic link in urban planning and construction.

The comprehensive disaster prevention evaluation of cities can provide a scientific basis for the safe layout of urban land use and comprehensive disaster prevention work. It has the characteristics of multidisciplinary intersections such as urban planning, disaster science, civil engineering and social economics. In recent years, relevant research fields are expanding. The evaluation method is also constantly improving and perfecting. In the field of evaluation, regional disaster system theory is still the main theoretical basis for analyzing urban comprehensive risk, that is, disaster is the product of the comprehensive effect of the earthquake surface environment, disaster-causing factors and disaster-bearing bodies on the Earth's surface. These three aspects are equally important for disaster prevention evaluation. The main entry point for current urban risk assessment is the evaluation of hazard factors, and the risk assessment shows a trend from single hazard to full hazard. As a huge disaster-producing environment and disasterbearing body with a high concentration of population, economy, information and infrastructure, the city has strong complexity, variability and uncertainty in the disastercausing mechanism, and its applicable evaluation model still In the research stage.

\section{II. "DOUBLE EVALUATION" MODEL CONSTRUCTION}

\section{A. Overview of the "Double Evaluation" model}

According to the regional disaster system theory, the city's comprehensive disaster prevention function is affected by the vulnerability, exposure and hazard factors of the city itself. This paper establishes a "double evaluation" model that emphasizes both "city assessment capacity assessment" and "hazard assessment of hazard factors", emphasizing the common impact of urban socio-economic factors and urban disasters on urban comprehensive disaster prevention functions.

The model uses the GIS platform to sort out the city's current disaster prevention resources, extract the evaluation elements, and score. The shortcomings of the city's normal stability and abnormal emergency are found, so that suggestions for improvement and planning countermeasures can be proposed in a targeted manner. At the same time, the model is dynamic and continuous. It regularly updates and improves the disaster prevention resource base map with the development of the city, and continuously evaluates and improves the city's disaster prevention and resilience(Fig. 1).

\section{B. Indicator system}

Based on the research on the comprehensive disaster prevention evaluation indicators of predecessors and the related documents on the comprehensive disaster prevention requirements of the city ${ }^{[2-4]}$, the "double evaluation" index system of urban comprehensive disaster prevention is constructed. The system consists of the target layer and three indicator layers(Fig. 2).

It should be noted that China's topography is changeable, so the index system of the evaluation model should also 


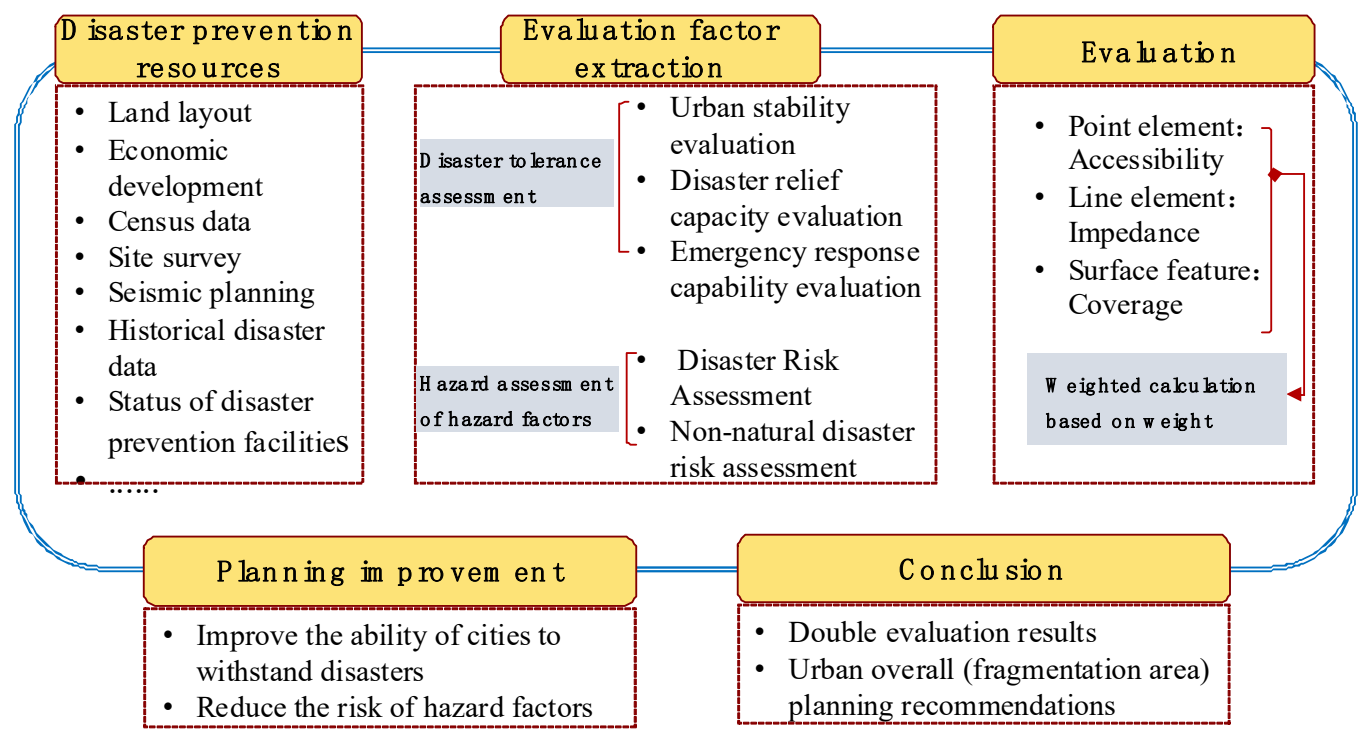

Fig. 1 Urban comprehensive disaster prevention "double evaluation" process

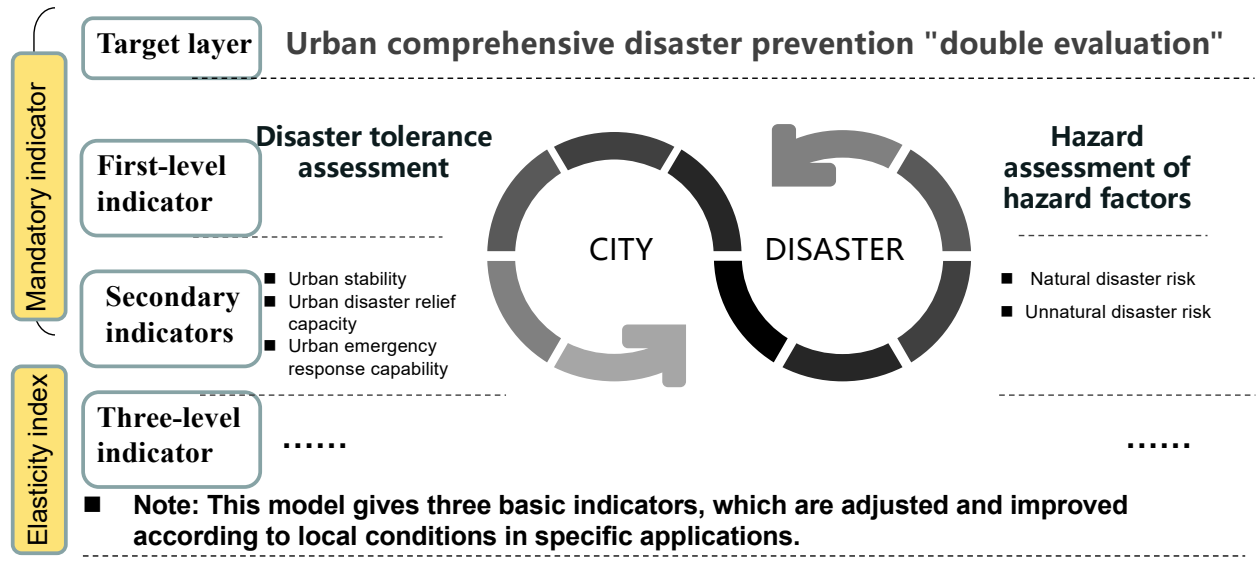

Fig. 2 The main indicators of comprehensive disaster prevention "double evaluation"

consider both universality and difference. Therefore, the target layer, the first-level index and the second-level index in the model are listed as hard indicators, which is the mandatory content of the evaluation system, which can guarantee the comprehensiveness of the evaluation system, while the third-level indicators are subject to the specific urban environment and the characteristics of the hazard factors. Due to the influence of multiple factors, there is a certain flexibility adjustment space. Therefore, in the specific evaluation process, the three-level indicators should be adjusted and improved on the basis of this model according to local conditions, and the relevant methods are used to obtain the weight.

\section{1) Evaluation of urban disaster tolerance}

Starting from the time series of urban disasters, the city's usual stability ability, disaster relief capacity and postdisaster emergency response capacity are listed as secondary indicators.

a) Urban stability: The urbanization rate, per capita GDP, convenience of public service facilities, urban development intensity, road network density and population mobility are selected as three-level indicators, which mainly consider the stability and order ability of the city in the normal operation process. Urbanization has improved the functional structure of the city, enabling it to further effectively control and govern the city and maintain urban public safety; Population mobility and urban development are the trends and inevitable social and economic development. On the one hand, it enhances the urban agglomeration and contributes to the efficient operation of the city. On the other hand, it also brings many unrest factors to the urban development. The data shows the largescale population movement. It is the main reason for the increase in the crime rate in China, and the proportion of the floating population in the total number of crimes is also rising ${ }^{[5-6]}$; The density of road networks and the convenience of public service facilities reflect the convenience of residents' travel, transportation and external contacts.

b) Urban disaster relief capacity. The city has the ability to resist and absorb disasters in the early stage of the disaster, and strive for a certain buffer time for the emergency escape of the crowd escape and disaster relief 
system, mainly considering the emergency response of the crowd and the stability of the building. The population density, the education level of the population, the age characteristics of the population, the investment in disaster prevention funds and the stability of the building are regarded as three-level indicators. Previous studies have shown that large population density, multiple vulnerable groups, and low education levels all have negative impacts on urban resilience ${ }^{[7-9]}$.

c) Urban emergency response capability. In the emergency rescue stage after the disaster, the city mainly shows the response and adaptability to the disaster, which is manifested by the accessibility of the shelter, the emergency response capability of the lifeline system, the emergency medical rescue capability, the fire protection system disaster relief capability and the accessibility of the urban road.

2) Hazard assessment of hazard factors.

China's urban disaster risk assessment research is relatively complete and mature. Due to the different formation mechanisms and effects of different hazard factors in cities, disaster classification has become the basic work of disaster risk assessment. According to the characteristics of hazard factors, this paper divides urban disaster risk into two categories: natural disasters and non-natural disasters, including geological disasters, earthquake disasters, meteorological disasters, flood disasters and accident disasters, fires, social security incidents, etc. And use its risk as a specific evaluation indicator ${ }^{[10-12]}$.

TABLE 1"Double Evaluation" Indicators and Weights for Comprehensive Disaster Prevention in New City Cities

\begin{tabular}{|c|c|c|c|c|c|c|c|c|}
\hline Target layer & $\begin{array}{l}\text { Primary } \\
\text { indicator A }\end{array}$ & $\begin{array}{l}\text { First- } \\
\text { level } \\
\text { indicator } \\
\text { weight }\end{array}$ & $\begin{array}{l}\text { Secondary } \\
\text { indicators B }\end{array}$ & $\begin{array}{l}\text { Secondary } \\
\text { indicator } \\
\text { weight }\end{array}$ & $\begin{array}{l}\text { Secondary } \\
\text { indicator } \\
\text { combination } \\
\text { weight }\end{array}$ & Three-level indicator $\mathrm{C}$ & $\begin{array}{l}\text { Three- } \\
\text { level } \\
\text { indicator } \\
\text { weight }\end{array}$ & $\begin{array}{l}\text { Three-level } \\
\text { indicator } \\
\text { combination } \\
\text { weight }\end{array}$ \\
\hline \multirow{20}{*}{$\begin{array}{l}\text { Urban } \\
\text { comprehensive } \\
\text { disaster } \\
\text { prevention } \\
\text { "double } \\
\text { evaluation" }\end{array}$} & \multirow{15}{*}{$\begin{array}{l}\text { A1 Urban } \\
\text { disaster } \\
\text { tolerance }\end{array}$} & \multirow{15}{*}{0.50} & \multirow{5}{*}{$\begin{array}{l}\text { B1 Urban } \\
\text { stability }\end{array}$} & \multirow{5}{*}{0.34} & \multirow{5}{*}{0.17} & C1 Urbanization rate & 0.12 & 0.0204 \\
\hline & & & & & & $\begin{array}{l}\text { C2 Public service facility } \\
\text { convenience }\end{array}$ & 0.30 & 0.0510 \\
\hline & & & & & & $\begin{array}{l}\text { C3 Urban development } \\
\text { intensity }\end{array}$ & 0.25 & 0.0425 \\
\hline & & & & & & C4 Road network density & 0.20 & 0.0340 \\
\hline & & & & & & C5 Population mobility & 0.13 & 0.0221 \\
\hline & & & \multirow{5}{*}{$\begin{array}{l}\text { B2 Urban } \\
\text { disaster relief } \\
\text { capacity }\end{array}$} & \multirow{5}{*}{0.31} & \multirow{5}{*}{0.15} & C6 The population density & 0.16 & 0.0248 \\
\hline & & & & & & C7 Population education & 0.19 & 0.0295 \\
\hline & & & & & & $\begin{array}{l}\text { C8 Population age } \\
\text { characteristics }\end{array}$ & 0.14 & 0.0217 \\
\hline & & & & & & $\begin{array}{l}\text { C9 Disaster prevention } \\
\text { fund investment }\end{array}$ & 0.24 & 0.0372 \\
\hline & & & & & & C10 Building stability & 0.27 & 0.0419 \\
\hline & & & \multirow{5}{*}{$\begin{array}{l}\text { B3 Urban } \\
\text { emergency } \\
\text { response } \\
\text { capability }\end{array}$} & \multirow{5}{*}{0.35} & \multirow{5}{*}{0.18} & C11 Refuge accessibility & 0.28 & 0.0490 \\
\hline & & & & & & C12 Road accessibility & 0.21 & 0.0368 \\
\hline & & & & & & $\begin{array}{l}\text { C13 Lifeline system } \\
\text { emergency effective } \\
\text { capability }\end{array}$ & 0.19 & 0.0333 \\
\hline & & & & & & $\begin{array}{l}\text { C14 Emergency medical } \\
\text { assistance }\end{array}$ & 0.15 & 0.0263 \\
\hline & & & & & & $\begin{array}{l}\text { C15 Fire protection system } \\
\text { disaster relief capability }\end{array}$ & 0.17 & 0.0298 \\
\hline & \multirow{5}{*}{$\begin{array}{l}\text { A2 Hazard } \\
\text { assessment } \\
\text { of hazard } \\
\text { factors }\end{array}$} & \multirow{5}{*}{0.50} & \multirow{3}{*}{$\begin{array}{l}\text { B4 Natural } \\
\text { disaster risk }\end{array}$} & \multirow{3}{*}{0.52} & \multirow{3}{*}{0.26} & C16 Geological hazard & 0.22 & 0.0572 \\
\hline & & & & & & $\begin{array}{ll}\text { C17 } & \text { Earthquake disaster } \\
\text { risk } & \\
\end{array}$ & 0.50 & 0.1300 \\
\hline & & & & & & C18 Flood disaster risk & 0.28 & 0.0728 \\
\hline & & & \multirow{2}{*}{$\begin{array}{l}\text { B5 Unnatural } \\
\text { disaster risk }\end{array}$} & \multirow{2}{*}{0.48} & \multirow{2}{*}{0.24} & C19 Fire hazard & 0.47 & 0.1128 \\
\hline & & & & & & C20 Accident hazard & 0.53 & 0.1272 \\
\hline
\end{tabular}

\section{A. Overview of the study area}

This paper selects Changping New City as the research object, and evaluates the urban disaster-resistance ability and hazard assessment of the six major components. Finally, the comprehensive evaluation results of urban comprehensive disaster prevention and the relative comprehensiveness of each area are obtained. The disaster prevention capability, and the overall disaster prevention planning measures for Changping New Town and the different countermeasures for each area are given.

\section{B. New City Comprehensive Disaster Prevention "Double Evaluation" Index System Architecture}

Firstly, the disaster prevention resources of Changping New Town will be sorted out, mainly including urban disaster data, urban land use layout data, urban population census data, urban public service facilities data, etc. The data comes from different departments and platforms, and further classified and classified to establish an index system. And using the combination of expert consultation and AHP to obtain the weight of each indicator(TABLE 1).

It can be seen from the above table that the evaluation of urban disaster-resistance capability and the risk assessment risk of the first-level indicators are equivalent, and play an equally important role in the comprehensive disaster prevention evaluation of cities. Among the urban disasterresistance indicators, the city's normal stability and disaster 
response have an impact on the city's disaster prevention functions, especially the convenience of public service facilities, demographic characteristics, and building stability. In disaster risk assessment, earthquake disasters have a large impact, and non-natural disasters such as fires and accidents also account for a large proportion.

\section{Urban disaster tolerance evaluation}

1) Evaluation of disaster response capability of the new city

According to the evaluation indicators and weights of Table 1, the stability ability, the disaster-resisting buffer capacity and the emergency response capability of each area were evaluated, and the results of the evaluation of the disaster-resisting ability of the new city were obtained (Fig. 3 ). The evaluation mainly includes the accessibility analysis of point elements, the impedance analysis of line elements, and the coverage analysis of surface elements. Taking the public service convenience index as an example, the indicator is a point element. In the GIS software, the accessibility of $300 \mathrm{~m}-500 \mathrm{~m}-1000 \mathrm{~m}$ is analyzed for the point facilities such as hospitals and stadiums according to the characteristics of the crowd activity, and the index is obtained $^{[13]}$.

According to the evaluation results of the disasterresistance capability (Fig. 4), it can be seen that the evaluation results of the disaster-resisting capacity of the new city show two steps, and the comprehensive scores of the Laocheng area, the South of Shahe area and the North of Shahe area are higher, the above three areas have better disaster-resisting capabilities than the rest.

\section{2) Hazard assessment of hazard factors}

According to the geographical location of the new city and historical disaster statistics, there are three main types of natural disasters that affect the new city, including earthquake disasters, geological disasters and flood disasters. Among them, geological disasters include collapse, landslides, etc. Flood disasters are dominated by urban floods, and earthquake disasters have a greater impact. Refer to China's relevant norms, conduct a risk assessment of natural disasters, and weight the new city natural disaster risk assessment (Fig. 5). It can be seen that the Baishan area is greatly affected by natural disasters, the east expansion area is relatively less affected, and the remaining areas are moderately affected.

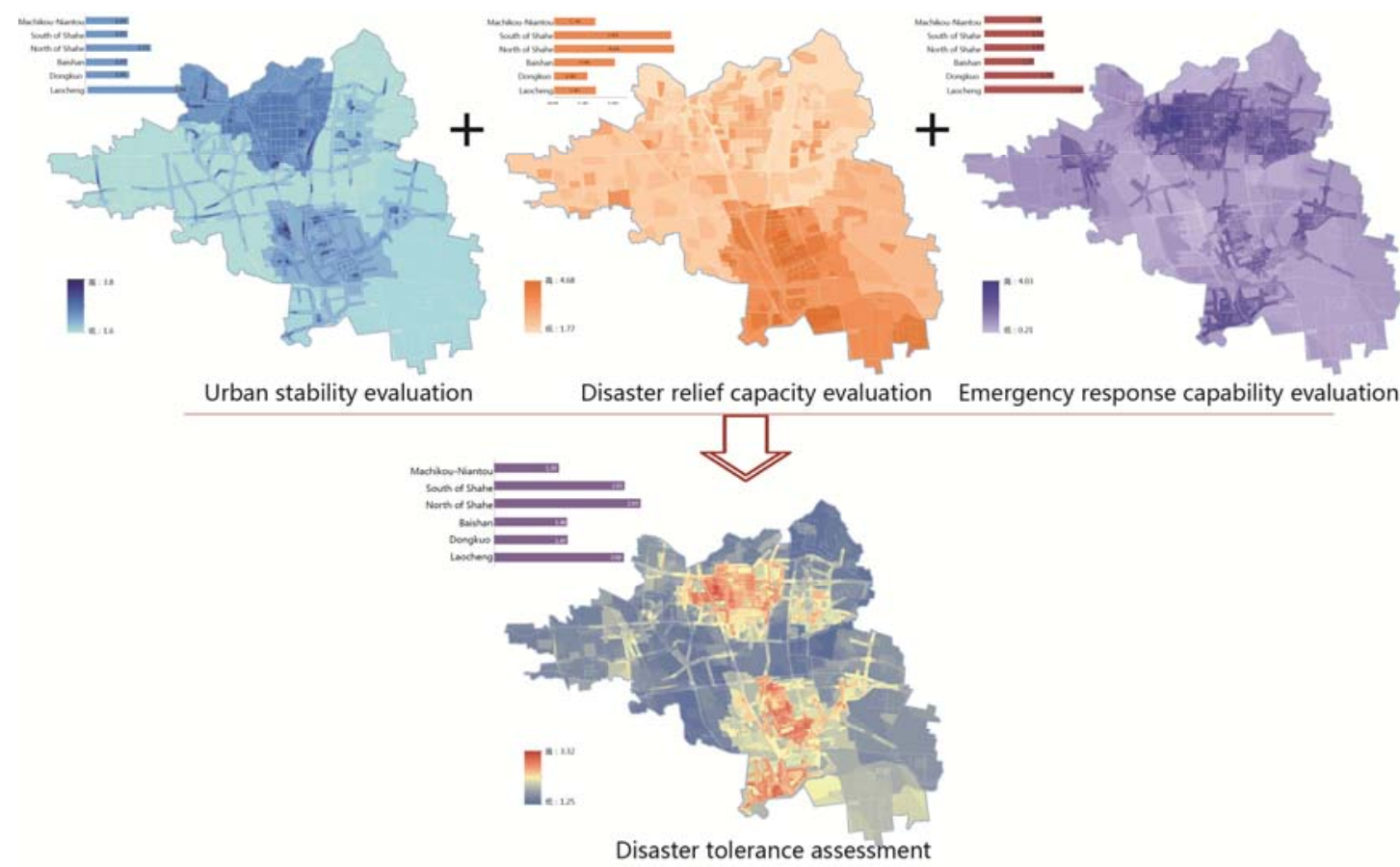

Fig. 3 Disaster tolerance assessment

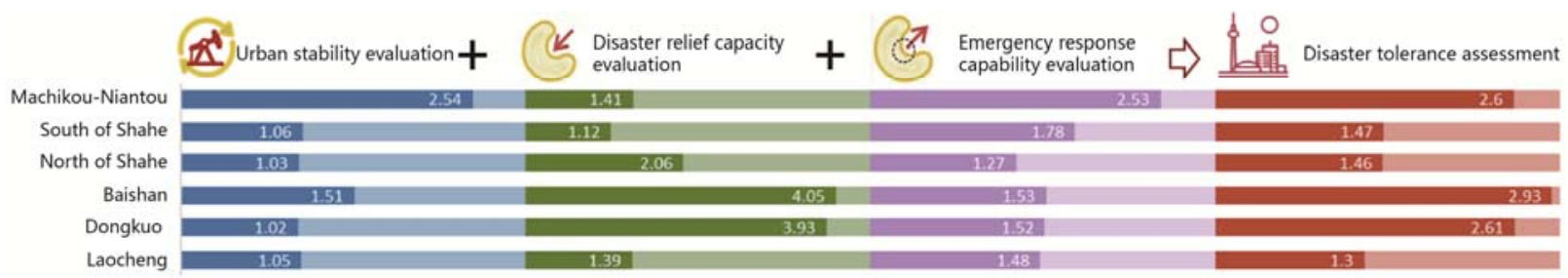

Fig. 4 Evaluation of the ability of each area to withstand disasters 
Non-natural disasters include accidents and fires, and the scope of impacts of non-natural disasters is defined according to the requirements of relevant regulations and secondary disasters of major hazards. Due to the large fire hazard, the risk of non-natural disasters in the Laocheng area is relatively high, and the evaluation results of the remaining areas are not much different.

Weighting the natural disaster risk and the risk of nonnatural disasters to obtain the risk of the new city hazard factor, as shown in Figure 5, the evaluation value is directly proportional to the hazard of the disaster. It can be seen that the earthquake has a great impact on the new city, and all the areas are affected by the earthquake disaster. The east expansion area is less affected and the overall disaster risk is lower (Fig. 6). risk, the weaker the comprehensive disaster prevention capability of the city. Therefore, in the final calculation, it is necessary to standardize the two indicators, and each of them is summed with a weight of 0.5 to obtain a comprehensive double-evaluation result of disaster prevention. Analyze the whole city and the various component areas, and find out the shortcomings of the new city's current disaster prevention and mitigation work, and propose planning countermeasures.

\section{a) Overall analysis and countermeasures}

The results of the "double evaluation" of the comprehensive disaster prevention of the new city are shown in Fig. 7-a. It can be seen that the overall safety suitability of the new city is quite different. The comprehensive evaluation of the Dongkuo Area, The South of Shahe Area and The North of Shahe Area is relatively high. Baishan Area and the

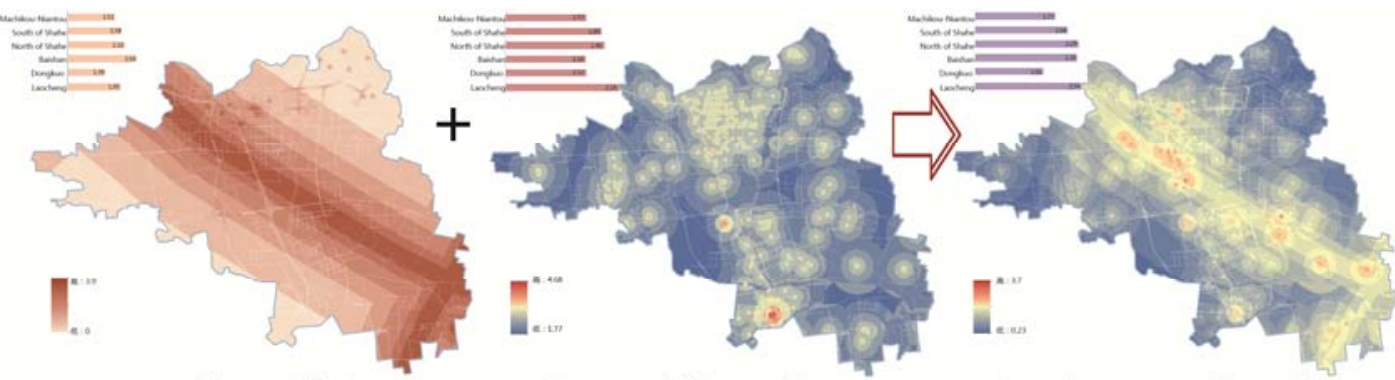

Disaster Risk Assessment

Non-natural disaster risk assessment

Hazard assessment of hazard factors

Fig. 5 Hazard assessment of hazard factors

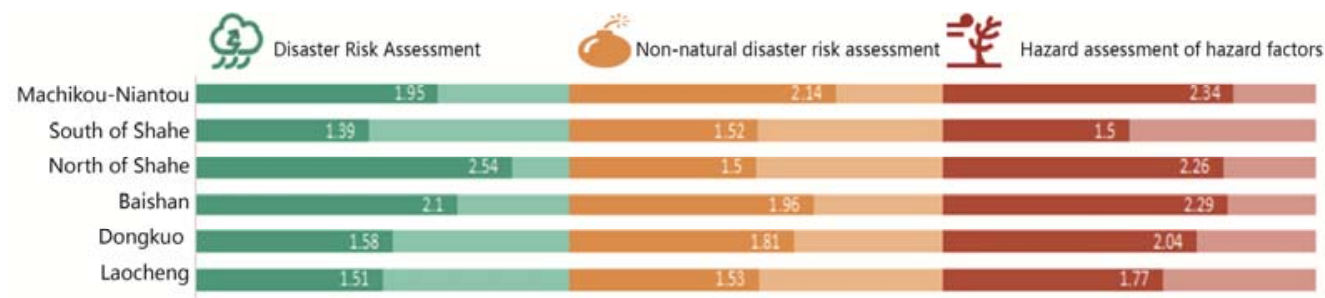

Fig. 6 Hazard assessment of hazard factors

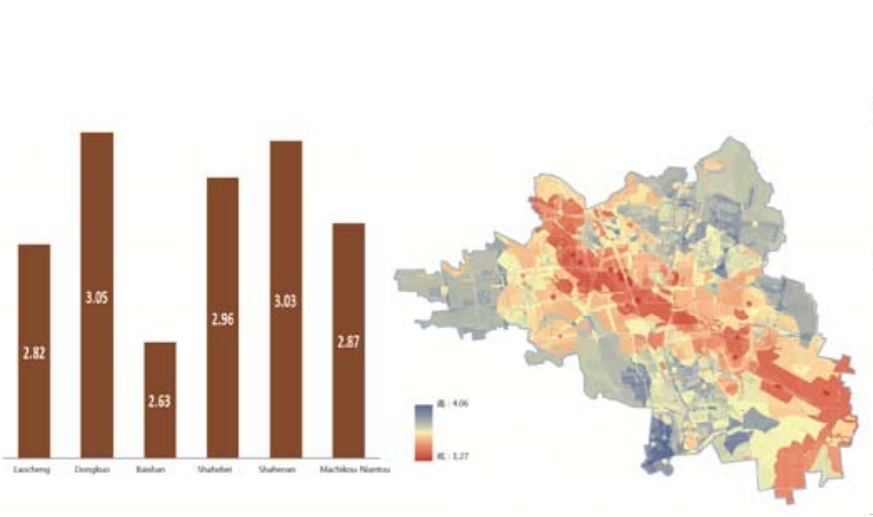

A Overall "double evaluation" results

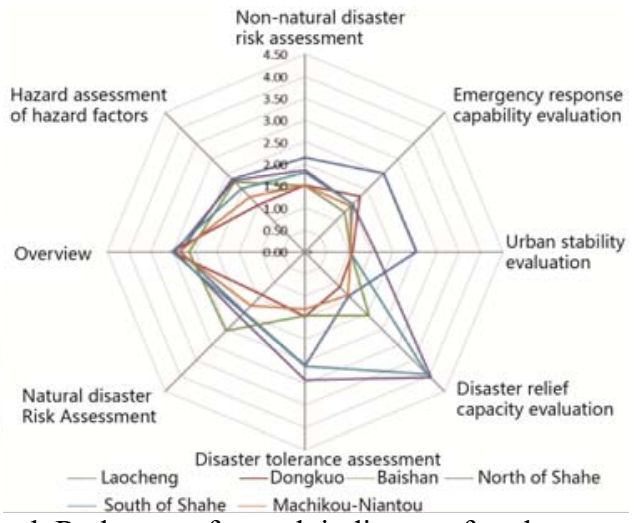

b Radar map for each indicator of each area

Fig. 7 New City comprehensive disaster prevention "double evaluation" results

\section{3) Result analysis and disaster prevention measures}

As the city's disaster-resistance capability has positive attributes for the "double evaluation" results, and the disaster risk has negative attributes, that is, the stronger the disastertolerant capability, the stronger the comprehensive disaster prevention capability of the city, and the greater the disaster
Laocheng Area Mainly affected by earthquake fault zone and fire, the safety suitability is low. At the same time, it also reflects the common problems in various districts, such as the small number of shelters, the weak service capacity of the lifeline system, and the large population mobility. 
From the perspective of improving urban security and resilience, the countermeasures for the overall planning of the new city are proposed: Urban construction should give priority to selecting areas with higher suitability, and appropriate engineering measures should be taken to improve the areas with lower suitability; Reasonably allocate public service facilities and disaster prevention facilities, increase the design of suitable facilities, increase the number of shelters, and strengthen and improve the lifeline system. It is necessary to improve the multi-investment mechanism of funds, conduct regular disaster prevention and evacuation drills, and conduct publicity and education on safety and disaster prevention.

b) Differentiation analysis and countermeasures of segmentation area

According to the comprehensive evaluation of each area and the second-level index evaluation radar chart, the advantages and shortcomings of the city's comprehensive disaster prevention function in each area are obtained, and the planning countermeasures are proposed (Fig. 7-b). In the same way, it is possible to analyze the evaluation of each area of each indicator, and also to view the evaluation of each indicator in a single area, to more intuitively reflect the shortcomings of disaster prevention and reduction, and further feedback to urban planning and construction.

- The development of the Laocheng area is relatively mature, the population density and building density are large, and there are many hidden dangers. The old city area has high stability and emergency response capability. However, due to the low disasterresistance buffer capacity and the high hazard factor, resulting in a comprehensive evaluation is not high. It is necessary to strengthen the renovation of old buildings in the region, reduce the hidden dangers of residential safety, and adopt engineering measures to improve the water accumulation points.

- The urban disaster relief capacity of the South of Shahe and the North of Shahe is better, but the disaster risk is greatly affected by earthquake disasters and fires, and the urban stability and disaster response capability are weak, so the overall comprehensive evaluation is not dominant. According to relevant regulations, certain safety measures should be taken for major hazards in the area and the risk avoidance distance should be divided.

- The Dongkuo area, Baishan area and the MachikouShantou area are in a disadvantaged position, and the overall evaluation is not much different, although the hazard factor is less dangerous. The urbanization of the district should be accelerated, the investment in disaster prevention funds should be increased, and the construction of public service facilities and emergency medical facilities systems should be improved.

\section{CONCLUSION}

This paper constructs a "double evaluation" model of urban comprehensive disaster prevention, which includes two aspects: "urban disaster-responsibility evaluation" and "hazard assessment of hazard factors". The characteristics of the model are reflected in: First, the comprehensiveness of the assessment, paying full attention to the two dimensions of "city" and "disaster"; second, the practicality of the indicator system, which divides the indicators into two categories: hard indicators and elastic indicators, which satisfy both applicability and uncertainty. The third is the rationality of the evaluation results. The evaluation values of each index can be viewed. The evaluation results are more intuitive and more oriented. The fourth is the dynamic persistence of the evaluation model. The evaluation is carried out at various stages of urban development, and the countermeasures for resilience improvement are proposed.

\section{REFERENCES}

[1] Shi Peijun. Re-discussion on the theory and practice of disaster research[J]. Journal of Natural Disasters, 1996, 11(4): 6-17.

[2] Tie Yongbo, Tang Chuan. Construction of Urban Disaster Emergency Response Evaluation Index System[J]. Urban Problems, 2005(6): 7679.

[3] Liu Yan, Kang Zhongyuan, Zhao Hanzhang, et al. Research on the comprehensive evaluation index system of urban disaster reduction management in China[J]. Journal of Natural Disasters, 1999(2): 6166.

[4] Zhang Ya-Nan. Research on Urbanization Safety Evaluation in Anhui Province [D]. 2018:15-17.

[5] Liu Ting, Lin Jun. Intergenerational Change of the Current Floating Population and the Evolution of Crime-An Empirical Study Based on Criminal Big Data[J].Journal of Chinese People's Public Security University(Social Science Edition),2018,34(06):1 -12.

[6] Bo Tang, Jinan Qiu, Jiaying Huang. Spatial and Temporal Patterns of Urban Vulnerability in Guangzhou. Journal of Risk Analysis and Crisis Response, 2019. 9(2): p. 101-110.

[7] Jia Ning. Research on government disaster protection projects and standards setting [D]. Zhejiang University, 2016: 80-83

[8] Hinkel J. "Indicators of vulnerability and adaptive capacity": Towards a clarification of the science-policy interface [J]. Global Environmental Change, 2011, 21(1): 198-208.

[9] Akerkar, S. Disaster Mitigation and Furthering Women $\backslash$ "s Rights: Learning from the Tsunami $[\mathrm{J}]$. Gender, Technology and Development, 2007, 11(3): 357-388.

[10] Urban comprehensive disaster prevention planning standards: GB/T 51327-2018 [S], 2018: 9-11.

[11] Yang Bing. Comprehensive Risk Assessment of Multi-Hazard Cities_-Taking Beijing as an Example [C]// Sharing and Quality-2018 China Urban Planning Annual Conference Proceedings (01 City Safety and Disaster Prevention Planning). 2018: 3-4.

[12] Huang Sheng. Research on Shanghai Comprehensive Disaster Reduction Management System [D]. East China Normal University, 2006; 4-5.

[13] Ran Maimei. Research on the space system of refuge in earthquake evacuation behavior psychology[D]. Southwest Jiaotong University, 2012:30-38. 